\title{
RISCO E AVENTURA NO ESPORTE NA PERCEPÇÃO DO INSTRUTOR
} RISK AND ADVENTURE IN SPORT: INSTRUCTOR'S PERCEPTION

\author{
Jairo Antônio da Paixão \\ Universidade Federal de Ouro Preto, Ouro Preto, Brasil \\ Ronaldo Eugênio Calçada Dias Gabriel \\ Universidade de Trás-os-Montes \& Alto Douro, Vila Real, Portugal \\ Guilherme Tucher \\ Faculdade de Minas, Muriaé, Brasil \\ Marizabel Kowalski \\ Universidade Federal de Viçosa, Viçosa, Brasil \\ Vera Lucia de Menezes Costa \\ Universidade Federal do Estado do Rio de Janeiro, Rio de Janeiro, Brasil
}

\begin{abstract}
RESUMO
O presente estudo analisa o risco na percepção de instrutores de esporte de aventura. A amostra foi constituída de 121 (cento e vinte e um) instrutores de diferentes modalidades de esporte de aventura praticadas em Minas Gerais, com média de idade de 31 (trinta e um) anos; considerou-se o desvio-padrão com significância $<0,05 \%$. Utilizou-se o método de estudo descritivo-exploratório. A coleta de dados se deu a partir de um questionário, validado em conformidade com a Técnica Delphi. Os resultados obtidos expressam que o risco percebido pelos instrutores é a forma mais genuína do risco-aventura provido do sentido lúdico. Ao se considerarem procedimentos e recomendações que visam prever, calcular e minimizar o risco imprevisto, verificou-se que a percepção do risco pelos instrutores decorre de uma atitude na qual prevalece a confiança no domínio da técnica e da qualidade dos equipamentos no momento dessas práticas corporais junto a natureza.
\end{abstract}

Palavras-chave: risco; percepção; instrutor; esporte de aventura.

\begin{abstract}
This study analyzes the risk perceptions of adventure sports instructors. The sample consisted of 121 (one hundred and twenty-one) instructors of different types of adventure sport practiced in Minas Gerais, with a mean age of 31 (thirty-one) years. It was considered the standard deviation with significance $><0,05 \%$. The exploratory method was used in this study. Data collection took place from a questionnaire, validated in accordance with the Delphi technique, containing 15 items based on the theoretical literature. The results express that the risk perceived by the instructors is the most genuine risk-filled adventure of the sense of play. When considering procedures and recommendations that aim to predict, calculate and minimize the risk unexpected, it was found that the perception of risk by the instructors is due to an attitude which prevails in the domain of technique and quality equipment at the time these bodily practices close to nature.
\end{abstract}

Keywords: risk; perception; instructor; adventure sport.

\section{Introdução}

Seguramente, o esporte encontra-se entre os maiores e mais emocionantes fenômenos socioculturais em escala mundial na contemporaneidade. Tamanha é sua abrangência que ele evidencia não somente a forma como a sociedade se organiza, como as contradições existentes em seu cotidiano (Callois, 1988; Elias, 1997; Parlebás, 2001).

Dentre a multiplicidade de elementos que delineiam o fenômeno do esporte destaca-se um permanente 
processo de evolução, surgindo ininterruptamente significados e ressignificados para a sua prática ao longo dos tempos (Elias, 1997).

Não importam os escritores, historiadores, romancistas, poetas, o fato é que o esporte permanece em um estado acessório de ocasiões para expor e ilustrar as ideias de identidades nacionais, como o bem, o belo, a natureza do homem, seus vícios e suas virtudes. O esporte se configura como sujeito e objeto no âmbito das relações que o homem estabelece na sociedade (Mandell, 1986).

Comparado às personagens lendárias e heroicas da história humana, o esportista apresenta frequentemente aos espectadores uma fonte obstinada de homens em oposição - faustianos e apolíneos e de hábitos dionisíacos. A atração exercida pela competição esportiva é uma modificação do instinto pela cultura. À medida que o esporte se manifesta em seus aportes mais profundos da representação social, coloca-se como reivindicação do instinto agonal humano (Huizinga, 1988).

A rápida inserção dos impulsos agonais no esporte e a necessidade de autoafirmação por via competitiva continuam sendo a dominante rotina da cultura ocidental. O indivíduo está cada vez mais impregnado disso, quase sempre sem saber, mesmo no momento em que os meios para satisfazer-se ficam mais escassos. Quando é demasiado intenso o desequilíbrio entre o fim e os meios, o risco aparece como um elemento que pode colocar voga a integridade física e emocional desses atores sociais (Elias, 1997).

A partir da transição paradigmática da modernidade para a pós-modernidade, surgem novas práticas corporais, entre elas as atividades esportivas na natureza (Betrán \& Betrán, 1995). Trata-se de uma vertente que elegeu os diferentes ambientes naturais como lócus privilegiado para a sua manifestação. Tendo como eixo norteador o risco da aventura, essas práticas corporais centram-se na (re)aproximação do homem com a natureza, na autorrealização, na competição, no lazer e na melhoria da qualidade de vida (Betrán \& Betrán, 1995; Costa, 2000; Marinho \& Bruhns, 2003).

Os impulsos lúdicos, caracterizados fundamentalmente pela busca por prazeres e pelo seu caráter desinteressado, manifestam-se, no caso específico dos esportes na natureza, pelo desejo de aventura. O prazer da aventura lúdica se realiza pelo desejo de vertigem. Daí a compreensão destes esportes como sendo "jogos vertiginosos", que nada mais são do que jogos que permitem experimentar, ao menos temporariamente, transtorno de estabilidade e de equilíbrio corporal, através de sensações de susto e pânico psicológico (Callois, 1988). Isso somado ao fato de que todo homem carrega em si o desejo de desafiar, desbravar, soltar-se das amarras da realidade para voar com a liberdade(Souza, 2004).
Nesses termos, sensações como vertigem, adrenalina, risco, fortes emoções e superação passaram a fazer parte da linguagem cotidiana daqueles que se entregam à aventura e ao risco calculado - características em que se fundamentam essas atividades (La Mendola, 2005). A aventura que se apresenta aos aventureiros nessa vertente esportiva se manifesta nos discursos com sentidos de exploração dos diferentes ambientes naturais (terrestre, aquático e aéreo). O risco os desafia, provoca medo e, ao mesmo tempo, remete-os ao prazer inigualável que é conferido ao elemento radical no esporte de aventura junto à natureza.

O surgimento ininterrupto de novas modalidades, acompanhado pelo crescente número de adeptos de diferentes formações culturais, faixas etárias, níveis sociais e campos de atuação profissional, fornece pistas para se entender o esporte de aventura como uma realidade no âmbito atual e que, por sua vez, apresenta inúmeras possibilidades de adesão e prática (Marinho \& Bruhns, 2003).

Ainda que a referida vertente esportiva apresente inúmeras possibilidades como prática corporal, faz-se importante ressaltar a necessidade de se considerar que, da mesma forma que ela pode propiciar inúmeros benefícios ao praticante, pode, na mesma proporção, colocar o praticante em situação de risco à sua integridade física.

Seja no âmbito da competição ou do lazer, a prática do esporte de aventura implica riscos de diferentes proporções, como quedas, colisões, escoriações, fraturas, afogamentos, congelamentos, mal-estar, entre outros (Ashcroft, 2001). A realidade mostra que, em alguns casos, apenas a utilização de equipamentos sofisticados não é suficiente para impedir um sério acidente (Bentley, Macky, \& Edwards, 2006; Cliff \& Page, 1996; Elmes \& Barry, 1999; Ewert, 1985).

A consideração do risco como elemento constitutivo da vida humana leva a (re)pensar a necessidade de o profissional encarregado da instrução de modalidades de esportes de aventura na natureza, seja no âmbito do lazer ou competição, trabalhar a questão da probabilidade da facticidade esportiva.

Quando a prática dessa vertente esportiva se encontra aliada a procedimentos e estratégias advindos de conhecimentos relativos a uma dada modalidade, há uma tendência a minimizar acidentes (Costa, 2000; Bentley, Macky, \& Edwards, 2006).

Dessa forma, o praticante deverá aliar uma série de saberes, que incluem domínio da técnica, habilidades adequadas à modalidade que está realizando, conhecimento e emprego da tecnologia e de equipamentos, capacidade de decifrar informações referentes ao ambiente natural e, diante do imprevisto, capacidade de decidir e agir antecipadamente por meio de estratégias a serem utilizadas para superar o obstáculo (risco objetivo) e 
atingir seus objetivos no decorrer do programa estabelecido para a prática esportiva. Esses conhecimentos deverão ser suficientes para assegurar ao praticante não somente o prazer e a aventura, como também sua integridade física e emocional, além de contemplar aspectos relacionados à preservação do meio natural em que se desenrola uma dada modalidade.

Essas considerações fornecem pistas para se refletir acerca do risco, das fortes emoções e da aventura propiciados pelas práticas corporais na natureza, que muitas vezes se efetivam em condições arriscadas. Uma vez que o risco se configura como elemento inerente e propulsor dessas atividades na natureza, é importante conhecer como os profissionais que se encontram à frente na condução e instrução de diferentes modalidades percebem e lidam com o risco no sentido de prever, controlar e minimizá-lo no cotidiano das intervenções profissionais.

Nesse sentido, o presente estudo buscou analisar a percepção dos instrutores de esporte de aventura sobre o risco na perspectiva de elemento constituinte das modalidades que se configuram nos diferentes ambientes naturais (terrestre, aquático e aéreo) praticadas no Estado de Minas Gerais.

\section{Sociedade e risco}

O lugar ocupado pelo risco na vida do homem em sociedade, como apresentado nos estudos de Giddens (1991, 2002) Beck (1993), Bernstein (1997), Le Breton (2000, 2004, 2006) e La Mendola (2005), é significativamente importante para compreender aspectos relacionados ao esporte de aventura como prática corporal. Ao relatar a história do risco, Bernstein (1997) mostra que até a época do Renascimento, quando as condições de vida eram atreladas à natureza, o futuro era percebido como uma questão de sorte ou resultado de variações aleatórias do ambiente. Ainda que as noções de risco que conhecemos hoje em dia não se aplicassem a essa época, o clima era a variável que mais provocava surpresas, pelo menos até as Cruzadas (Bernstein, 1997).

A proximidade do perigo como fator de risco de vida na sociedade é uma questão do conhecimento dos princípios de probabilidades da "facticidade" que passam a ser estudados a partir do final do século XIII e início do XIV, estabelecendo a materialidade dos homens em declínio do feudalismo, subjugo da igreja católica e evolução científica no desenvolvimento das ciências. Já a administração do risco passa a ter como objeto a probabilidade "do acontecer" junto às reações subjetivas, o controle da emoção e, acima de tudo, a superação da natureza, cujas decisões chegam a ultrapassar o limite do risco. Também a competição e a luta pela sobrevivência na sociedade ao mesmo tempo nos atraem e nos atemorizam, e percebemos que delas não podemos fugir.
A sociedade contemporânea tem sido conceitualizada como a sociedade do risco (Beck, 1993; Giddens, 1991, 2002; Martín, 1996). Nessa perspectiva, Martín (1996) a discute a partir de quatro enfoques: institucional, sistêmico, semiótico e fenomenológico.

Institucionalmente, o risco é relacionado ao processo iniciado com a revolução industrial, cujas consequências são problemas ecológicos, desemprego e insegurança. Inclui como alvo e fonte de risco o sistema familiar, a estratificação social e a administração pública com tomadas de decisão. Sistematicamente, o problema do risco é abordado na sociedade contemporânea sob a ótica da contingência e da complexidade. A semiótica faz uso das ideias de Baudrillard, relevando o individualismo narcisista que surge da deserção generalizada dos valores e finalidades sociais, provocada pelo processo de personalização. Ao gerar vazio social, tal situação, coloca em cheque a própria sociedade. Finalmente, a fenomenologia tem por base Giddens (1991), para o qual na cultura do risco, que se configura como a própria modernidade, a pessoa cada vez mais deverá ser capaz de assumir o pacote de riscos que acompanha sua atividade no mundo. Nesses termos, o risco acompanha o devir na trajetória do individuo no processo de humanização.

Por outro lado, o risco para Le Breton (2006) aparece nas sociedades como um dado antropológico que atravessa todos os registros da condição humana, da responsabilidade para com os outros à preservação física $\mathrm{e}$ moral de si mesmo. As comunidades repelem ritualmente os medos com preces, cerimônias coletivas, modos de organização que contêm a adversidade. A partir dos discursos sobre o risco, Spink (2000) e Spink e Menegon (2004) destacam três tradições discursivas que buscam explicar o risco de formas específicas. Na primeira tradição, o risco na fala do senso comum refere-se às experiências de infortúnios e imprevisibilidades que na maioria das vezes fogem das possibilidades de cálculo. É uma tradição raramente considerada nas análises de risco, mas que certamente se faz presente nas análises discursivas dos modos de falar sobre risco no cotidiano. Na segunda, a perspectiva do controle e disciplina nos remete à perspectiva histórica dos discursos sobre risco relacionado à crescente necessidade de governar populações, a partir da modernidade clássica. Foucault (2007) denomina essas ações por governamentalidade. Como exemplo, tem-se a tomada de medidas coletivas, destinadas a gerenciar relações espaciais - distribuição e movimento de pessoas nos espaços físicos e sociais. Somam-se a essa perspectiva os processos de disciplinarização da vida privada das pessoas. Nesses processos de disciplinarização, o indivíduo, mediante acesso à informação, passa a ser responsável pelo autogerenciamento de sua própria saúde. O estilo de vida como forma de autocontrole é a face mais famosa dessa reorganização. 
Por fim, na terceira tradição, a perspectiva da aventura balizada pelos campos do esporte e da economia veicula a mensagem de que correr riscos é uma prática necessária para que o indivíduo alcance determinados ganhos na sociedade. O risco, nesta perspectiva, configura-se como algo desejado pelos indivíduos (Spink, 2000; Spink \& Menegon, 2004).

Como resultado das pesquisas realizadas a partir das práticas discursivas sobre risco (Spink, 2001; Spink, Medrado, \& Mello, 2002), foi possível elaborar três dicionários específicos sobre o risco, nos quais aparecem os verbetes: risco-perigo (primeira tradição), risco-probabilidade (segunda tradição) e risco-aventura (terceira tradição), como se pode observar na Tabela 1.

Tabela 1

Significados atribuídos ao risco.

\begin{tabular}{lll}
\hline \multicolumn{1}{c}{ Risco-perigo } & Risco-probabilidade & Risco-aventura \\
\hline Ameaça & Risco & Aventura \\
Perda & Aposta & Adrenalina \\
Sorte & Chance & Emoção \\
Perigo (perigoso) & Seguro (segurança) & Radical \\
Azar & Probabilidade & Extremo \\
Fortuna (do) & Prevenir (prevenção) & Desafio \\
Fatalidade & Arriscar (arriscado) & Ousadia \\
Obstáculo & & \\
Ventura & & \\
Destino & & \\
\hline
\end{tabular}

Fonte: Spink 2001 e Spink; Medrado e Mello (2002).

É possível perceber que as designações atribuídas ao risco acabam contribuindo para melhor compreensão dos significados e sentidos que damos às nossas ações e experiências na vida cotidiana, considerando o contexto da sociedade atual.

Outra situação, percebida tanto no turismo como no esporte de aventura, é a inexistência de uma estimativa precisa de acidentes em nível mundial. Entre as prováveis causas, estudiosos atribuem ao fato de os experts em relações públicas envolvidos direta ou indiretamente nesse setor temerem que tal divulgação, de alguma forma, possa comprometer os negócios em regiões que dependem economicamente dessas práticas físicas (Bentley \& Page, 2008; Bentley, Page \& Laird, 2001; Costa, 2000; Wilks \& Atherton, 1994).

\section{Prática corporal e risco}

O homem sempre conviveu com situações de risco ligadas aos fenômenos naturais e climáticos, perpassando os quatro elementos - fogo, ar, terra e água - secas pertinentes, regiões áridas, geladas e desérticas, verões escaldantes acompanhados de incêndios, terremotos e ventanias, invernos glaciais e chuvas torrenciais
(Ashcroft, 2001). No entanto, com a evolução da ciência e os avanços tecnológicos já no final do século XIX e início do XX, o homem se coloca diante de novos riscos. Na maioria das vezes, esses novos riscos são vivenciados em práticas físicas na natureza e, em alguns casos, dependendo do tipo de ocupação profissional, constituem parte inevitável do trabalho. Percebe-se a existência de uma velha conexão entre risco e aventura, valorizada pela ousadia, que pode levar o indivíduo a inúmeras descobertas (Ashcroft, 2001).

Essa conexão é observada nas diferentes modalidades que atualmente compõem o esporte de aventura na natureza. O risco-aventura surgiu na década de 1970 com a modalidade de esporte de aventura denominada off-the-road, em provas como o Rali Paris-Dakar em 1979 e o Camel Trophy na década de 1980, em diferentes países (Beck, 1993; Spink, 2001). A consideração do risco como elemento constitutivo das diferentes dimensões que compõem a vida humana - que, por meio dos avanços tecnológicos, proporcionam novas possibilidades de vivenciar o risco, como, por exemplo, a prática das diferentes modalidades de esporte de aventura - leva a (re)pensar a necessidade de o profissional encarregado da sua condução, seja no âmbito do lazer ou competição, trabalhar essa questão com os seus alunos, buscando não somente muni-los de informações técnicas como ainda conscientizá-lo da importância de calcular o risco, vivenciá-lo sem, mas sem expor perigosamente sua vida e a de outros.

Apesar da necessidade de procedimentos que visam à integridade física e emocional dos praticantes das diferentes modalidades de esporte de aventura, tais procedimentos apresentam-se como uma faca de dois gumes, ou seja, o controle total dos riscos eliminaria a atratividade e as fortes emoções buscadas pelos praticantes (Elias, 1993; Morgan \& Fluker, 2006; Page, Bentley, \& Walker, 2003; Ryan, 2003). Nessa perspectiva, ao se adotarem procedimentos no sentido de controlar o risco, há de considerar variáveis como nível da atividade e habilidades do praticante (Bentley, Macky, \& Edwards, 2006; Wilks \& Atherton, 1994).

No caso de algumas modalidades, como o voo livre, é preciso que o praticante domine todas as técnicas de voo, além das informações meteorológicas, o cálculo atento da probabilidade e possibilidade de risco é de extrema urgência e de permanente prescrição para que o esporte seja realizado com tranquilidade e lhe proporcione prazer. Ainda assim, observam-se alguns casos de acidentes, em que o praticante - por imprudência, distração ou falta de controle - pode vir a correr risco, machucar-se ou até mesmo perder a vida.

Da mesma forma, em outras modalidades de esporte de aventura, os procedimentos que visam controlar os riscos mostram-se cada vez mais imprescindíveis 
ao praticante consciente que se lança em diferentes ambientes naturais na busca incessante por fortes emoções. O praticante pode aliar uma série de saberes, que incluem o domínio da técnica, habilidades adequadas à modalidade praticada, conhecimento e emprego da tecnologia e de equipamentos, capacidade de decifrar informações referentes ao ambiente natural e, em face do imprevisto, capacidade de decidir e agir antecipadamente por meio de estratégias a serem utilizadas para superar os obstáculos (risco-objetivo).

Esses conhecimentos nem sempre são suficientes para assegurar ao praticante sua integridade física e emocional, mas a somente a superação do desconhecido, das intempéries e dos imprevistos poderá lhe dar prazer e contemplar a aventura. Entretanto, além de tudo isso, deve-se manter intocáveis os aspectos relacionados à preservação do meio ambiente natural em que se desenrola o esporte, a aventura e o prazer.

Essas considerações fornecem elementos para se questionar o tipo de instrução recebida pelos praticantes: esses atores, ao buscarem essas práticas em condições arriscadas e num movimento de procura incessante de emoções e de lugares especiais, o estão fazendo sob a segurança de um condutor profissional competente ou foram instruídos de igual forma antes de se autonomizar em atividades dessa natureza, minimizando os riscos a que podem vir a ser submetidos?

\section{$O$ instrutor de esporte de aventura: contexto no Brasil}

Por meio de observações empíricas e da produção científica que aborda o esporte de aventura, observa-se a inexistência no Brasil de formação oficial específica para o profissional que trabalha com o esporte de aventura, como ocorre, por exemplo, com os profissionais de Educação Física. Como afirma Costa (2005), geralmente esses profissionais se autoformam ou recebem um curso de mínima duração por intermédio de algumas confederações esportivas ou de associações internacionais certificadoras.

Apesar de o esporte de aventura ser uma realidade em termos de prática física no cenário brasileiro, seja no âmbito do lazer ou da competição, verifica-se que as discussões geradas sobre o profissional que se encontra à frente do processo instrucional das diferentes modalidades de esporte de aventura ainda não contemplam em maior magnitude questões e implicações que a temática demanda. Essa vertente esportiva configura-se no Brasil num contexto inovador e promissor, fato esse que contribui sobremaneira para que tenhamos ainda um número reduzido de pesquisadores que buscam oportunizar conhecimentos qualitativos para a formação profissional capacitada e que contribuam efetivamente para o atendimento da demanda dessa prática corporal na natureza.
A categoria na qual se insere o instrutor do esporte de aventura no Brasil não dispõe ainda de um status $^{l}$ suficientemente capaz de propor uma sistematização das ações, estratégias e procedimentos adotados por esses atores à luz da Pedagogia (nos domínios da didática). Esse status configurar-se-ia numa espécie de referência para a organização e o desenvolvimento do trabalho docente, dadas as novas necessidades sociais da contemporaneidade observadas na vertente do esporte de aventura.

\section{Método}

Metodologicamente, o estudo caracteriza-se como descritivo-exploratório de campo, que tem como características observar, registrar, analisar, descrever, correlacionar fatos ou fenômenos sem manipulá-los, procurando descobrir com precisão a frequência com que o fenômeno ocorre e sua relação com outros fatores (Drake \& Miller, 1969; Malhotra, 2001). O delineamento da configuração dos dados foi feito com base nos pressupostos da pesquisa Survey (Babbie, 2001; Gil, 2008). No processo de construção e validação do instrumento de coleta de dados foi empregada a técnica Delphi (Duffield, 1993; Thomas \& Nelson, 2002), a partir de uma sucessão de pareceres de três professores doutores especialistas na área, num total de quatro fases, quando se obteve consenso no tocante às questões investigativas sobre a percepção do risco pelos instrutores de esporte de aventura.

Foi empregado como instrumento de coleta de dados um questionário, contendo 15 itens baseados nos pressupostos teóricos da literatura especializada sobre o risco (Le Breton, 2006). Os itens foram organizados a partir de duas categorias: aqueles cujas variáveis foram avaliadas a partir de questões abertas e outra na qual se encontravam as questões fechadas, em que as variáveis foram avaliadas a partir de uma escala bipolar do tipo Likert, variando de 1 a 7 (com ponto médio igual a 4). Nessa segunda categoria do questionário, para cada item avaliado, havia nas extremidades as opções extremamente provável a extremamente improvável para um determinado comportamento.

Para o grupo amostral, buscou-se considerar os instrutores que, de acordo com a(s) modalidade(s) de atuação, se encontravam vinculados a empresas associadas a uma federação de esporte de aventura do Estado de Minas Gerais. A população total constituiu-se de 237 instrutores, responsáveis pela condução de 19 modalidades no estado (Figura 1). A definição da amostra foi realizada de forma probabilística. Essa opção foi feita com o intuito de garantir a representatividade dos resultados obtidos. Dessa forma, a amostra totalizou 121 sujeitos. Em razão da distância em que se encontravam os instrutores, a coleta de dados foi realizada através dos seus e-mails. 
Para esse fim, foi elaborada uma carta explicativa sobre o estudo e a importância da contribuição desses sujeitos para a efetivação da pesquisa. Juntamente com o questionário e a referida carta explicativa, foi encaminhado aos sujeitos do estudo o Termo de Consentimento Livre e Esclarecido. A coleta de dados foi feita entre os meses de fevereiro e setembro de 2009. As análises estatísticas foram realizadas por meio de estatística descritiva.

\section{Análise dos dados - resultados e argumentações}

Verificou-se em sua totalidade $(100 \%)$ que os entrevistados atuantes como instrutores de esporte de aventura eram do sexo masculino, com média de idade de aproximadamente 31 anos; considerou-se o desvio-padrão com significância $><0,05 \%$. Pode-se interpretar que, embora haja adesão das mulheres à prática do esporte, elas não se apresentaram no papel de instrutoras. Quanto ao de tempo de atuação profissional como instrutores, constatou-se a média de 7,2 anos, com desvio-padrão de 3,9.

No que se refere às modalidades trabalhadas pelos instrutores, verificou-se que eles atuam em mais de uma modalidade de esporte de aventura. A escalada aparece como a modalidade de esporte de aventura mais praticada no Estado de Minas Gerais. Esse fato se explica pela geografia da região, que oferece aos praticantes um conjunto de montanhas e relevos com altitudes diversificadas, que facilitam não somente a prática da referida modalidade, como ainda de outras, como tirolesa, rapel e asa delta, como pode ser observado no Gráfico 1.

Gráfico 1

Modalidades de esporte de aventura em que os entrevistados atuam como instrutores.

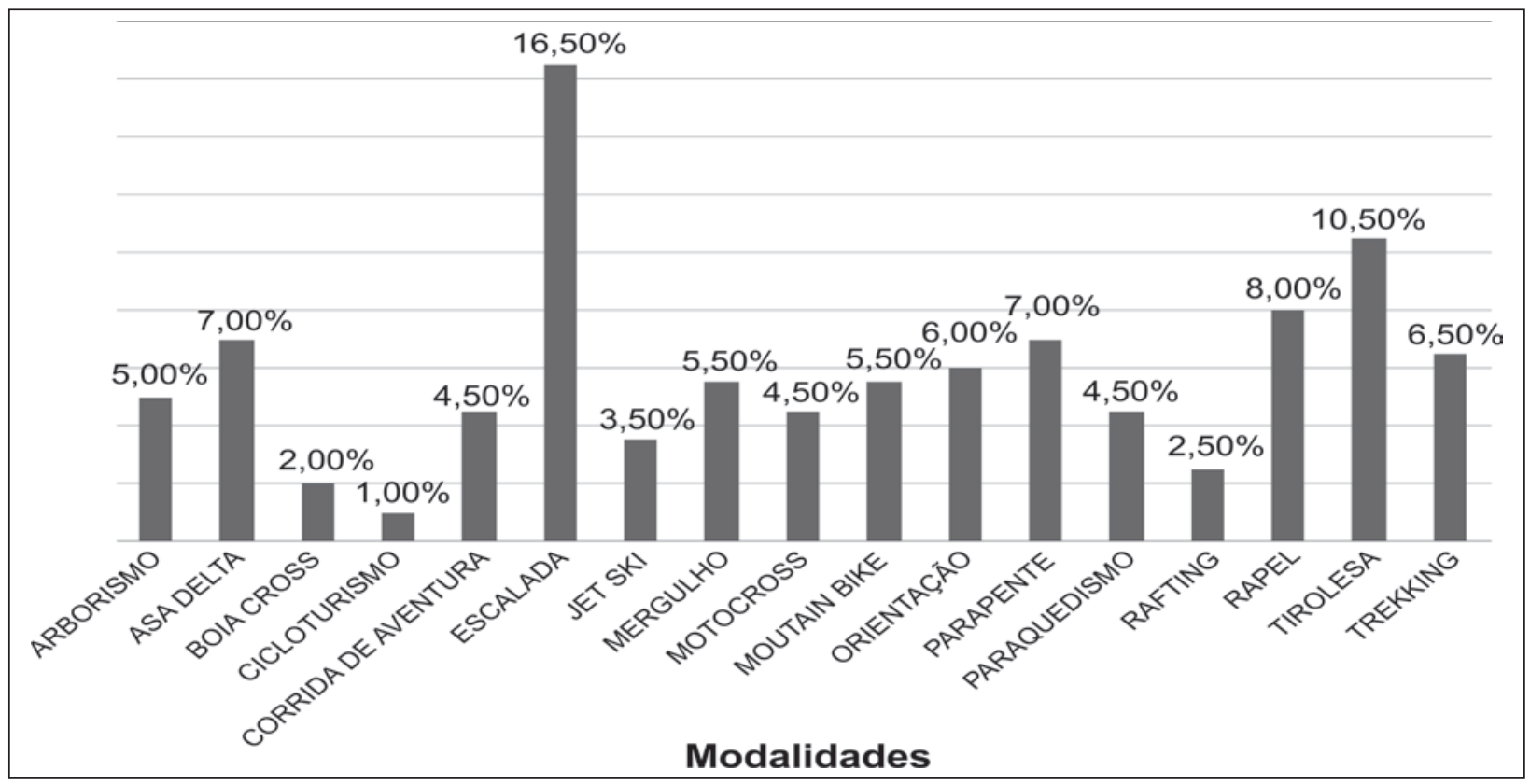

Trata-se de uma atividade profissional que se realiza em sua grande maioria na informalidade e não desfruta de reconhecimento oficial como profissão, salvo entre determinadas instituições esportivas. Conforme observado no grupo amostral, a maioria dos instrutores $(71,07 \%)$ possui formação em nível superior. Os demais, 35 (28,57\%), com o ensino médio, atuam profissionalmente no mercado informal, em instituições públicas, comércio e em outros segmentos da sociedade. No que se refere à área de formação, constatou-se que 37 (43,02\%) instrutores eram formados em Educação Física e 49 (57,97\%) em diferentes áreas, como Direito, Administração de
Empresas, Engenharia Civil, Engenharia Florestal, Mecatrônica, Agronomia, Turismo, Fisioterapia, Ciências da computação, Letras e Psicologia.

Esses dados indicam uma situação intrigante para a categoria de instrutores que atuam em práticas esportivas de lazer e/ou competição com aventura e risco junto à natureza: o campo de intervenção profissional no Brasil não apresenta regulamentação. Em outras palavras, trata-se de um campo de atuação em que, pela falta de normatização e status da categoria profissional de instrutor de esporte de aventura, inexiste a exigência de formação acadêmica, seja em nível profissionalizante ou superior, para a atuação (Costa, 2005). 
No âmbito do processo instrucional, buscou analisar a percepção do instrutor quanto à ocorrência ou não de situação de risco junto aos aprendizes. $\mathrm{O}$ resultado indica um percentual considerável de ocorrência $(57 \%)$, porém sem grandes discrepâncias, com $43 \%$ sem ocorrência de situações de risco, como se observa na Tabela 2.

Tabela 2

Ocorrência de situações de risco com aprendizes no decorrer do processo instrucional de esporte de aventura

\begin{tabular}{l|c|c}
\hline \multicolumn{1}{c|}{ Situações de risco } & $\mathbf{n}$ & $\mathbf{\%}$ \\
\hline Alegaram ocorrência & 69 & 57 \\
Não alegaram ocorrência & 52 & 43 \\
\hline \multicolumn{1}{c|}{ Total } & $\mathbf{1 2 1}$ & $\mathbf{1 0 0}$ \\
\hline
\end{tabular}

Informações relativas a cuidados visando à própria segurança e preservação do meio natural parecem não fazer parte da mensagem que se quer veicular. Há relatos de ocorrência de entorses, fraturas, tonturas e escoriações - estas últimas são consideradas pelos instrutores ocorrências normais na fase de aprendizado de outras modalidades de esporte. Já a não prevalência de situações de risco envolvendo aprendizes no decorrer do aprendizado, segundo discurso dos instrutores, está relacionada aos avanços tecnológicos na produção de equipamentos específicos para o esporte de aventura.

No que se refere aos procedimentos considerados imprescindíveis no sentido de evitar e/ou minimizar situações de risco, os resultados indicam os aspectos ligados ao domínio da técnica e dos equipamentos empregados.

Em decorrência da importância atribuída por esses atores ao domínio da técnica e bom estado dos equipamentos no sentido de maximizar a aventura e controlar os riscos, são apresentados na Tabela 3 os itens referentes à percepção dos instrutores quanto à importância do domínio da técnica, bem como da qualidade, manutenção e estado dos equipamentos empregados na prática das diferentes modalidades. De maneira geral, não foram verificadas diferenças significativas entre os itens analisados. Os instrutores, em sua maioria, percebem o domínio da técnica, a manutenção e a qualidade dos equipamentos na faixa de extremamente e bastante prováveis de minimizar os riscos de acidentes.

Tabela 3

Percepção dos instrutores quanto a técnica e equipamentos de esporte de aventura

\begin{tabular}{lcccc}
\hline \multirow{2}{*}{ CLASSE } & \multicolumn{4}{c}{ ITENS INVESTIGADOS - F (\%) } \\
\cline { 2 - 5 } & $\begin{array}{c}\text { Domínio da técnica } \\
\text { pelo praticante }\end{array}$ & $\begin{array}{c}\text { Bom estado dos } \\
\text { equipamentos }\end{array}$ & $\begin{array}{c}\text { Certificação do nível de } \\
\text { segurança do equipamento }\end{array}$ & $\begin{array}{c}\text { Checagem prévia dos } \\
\text { equipamentos pelo praticante }\end{array}$ \\
\hline Extremamente $(+)$ & $88,07 \%$ & $66,05 \%$ & $54,13 \%$ & $75,23 \%$ \\
Bastante $(+)$ & $11,93 \%$ & $29,36 \%$ & $34,86 \%$ & $24,77 \%$ \\
Um pouco $(+)$ & -- & $4,59 \%$ & $11,01 \%$ & -- \\
Nem um, nem outro $(+/-)$ & -- & -- & -- & -- \\
Um pouco $(-)$ & -- & -- & -- & -- \\
Bastante $(-)$ & -- & -- & -- & -- \\
Extremamente $(-)$ & -- & -- & $100 \%$ & $100 \%$ \\
TOTAL & $100 \%$ & $100 \%$ & &
\end{tabular}

Entre os procedimentos e medidas no sentido de prever, minimizar e controlar os riscos no momento da prática das modalidades de esporte de aventura, percebeu-se consenso na percepção dos instrutores no tocante à sua importância. Le Breton (2000), ao discutir a pedagogia do risco, afirma que as experiências adquiridas e a integração gradual das técnicas minimizam as ameaças ou as circunscrevem a pontos onde se exerce vigilância. A menor desatenção pode causar sérios problemas. Há de se considerar ainda que a prática de esporte de aventura, estimulada pelo desenvolvimento da pesquisa científica tanto na melhoria da performance técnica como na produção de material, possibilita cada vez mais ao praticante vivenciar as fortes emoções dentro de uma margem de controle do risco, como, por exemplo, a cada vez que o praticante se atira num salto de parapente ou escala um paredão íngreme na escalada.

No que se refere aos procedimentos a serem considerados nos momentos que antecedem a prática de uma modalidade de esporte de aventura em um ambiente natural distinto como o aéreo, terrestre ou aquático, os resultados apresentados na Tabela 4 mostram significativa variabilidade entre as percepções dos instrutores quanto à relevância dos itens 'consideração prévia das condições meteorológicas' e 'conhecimento prévio do ambiente natural de prática', no sentido de diminuir e/ou prever os riscos. 
Tabela 4

Percepção dos instrutores quanto aos procedimentos prévios.

\begin{tabular}{ccc}
\hline & \multicolumn{3}{c}{ ITENS INVESTIGADOS - F (\%) } \\
\cline { 2 - 3 } CLASSE & $\begin{array}{c}\text { Consideração } \\
\text { prévia da } \\
\text { meteorologia }\end{array}$ & $\begin{array}{c}\text { Conhecimento } \\
\text { prévio do } \\
\text { ambiente natural } \\
\text { de prática }\end{array}$ \\
\hline Extremamente $(+)$ & $33,02 \%$ & $18,35 \%$ \\
Bastante $(+)$ & $26,60 \%$ & $25,69 \%$ \\
Um pouco $(+)$ & $22,02 \%$ & $29,36 \%$ \\
Nem um nem outro $(+/-)$ & $12,85 \%$ & $16,51 \%$ \\
Um pouco $(-)$ & $5,51 \%$ & $10,09 \%$ \\
Bastante $(-)$ & -- & -- \\
Extremamente $(-)$ & -- & -- \\
TOTAL & $100 \%$ & $100 \%$ \\
\hline
\end{tabular}

Uma situação que chama a atenção é o fato de os mesmos sujeitos em sua totalidade perceberem a relevância do domínio da técnica e da qualidade dos equipamentos de prática e de, no entanto, persistir acentuada variabilidade de percepção da importância da adoção de procedimentos prévios à prática, como aqueles relacionados à previsão meteorológica, como mudanças repentinas nas massas de ar, tempestades e outras intempéries. O conhecimento prévio do ambiente natural de prática - como as características dos relevos, os possíveis locais de pouso e a potência das térmicas - é um dos aspectos relacionados ao risco de voar e, por sua vez, poderá contribuir para minimizar os riscos (Bentley \& Page, 2008). Visto dessa forma, os resultados indicam que o ambiente natural, na percepção dos instrutores, apresenta-se tão-somente como um cenário para as práticas aventureiras. Contudo, a natureza é dinâmica e proporciona cada vez mais seu poder de reação e mudanças, ora de forma imperceptível, ora de forma surpreendente (Guattari, 2006).

Embora o esporte, como afirma Horn (2002), tenha uma tendência a domesticar o ambiente, formalizá-lo, impor-lhe regras, é no meio natural - ênfase neste estudo no ambiente aéreo, onde é quase impossível controlar as informações que podem orientar as decisões dos praticantes - que se afirma a necessidade de aprender a ler os obstáculos, decifrar as artimanhas da velocidade e direção do vento e da temperatura, para decidir a melhor intervenção. É essa incerteza informacional que provoca e compõe o desafio dessa prática corporal na natureza. Lidar com ela é que desenvolve a ousadia desses aventureiros e desencadeia-lhes o prazer na atividade.

A incerteza, elemento presente nos esportes de risco, para Bernstein (1997), é encontrada também nos processos de tomadas de decisão, uma vez que o risco está em suas consequências e o elemento surpresa, aleatório, é comum num sistema que depende de previsibilidade e probabilidade. Isso mostra que, a despeito de toda a racionalização que se empregue para a maximização da utilidade dos resultados, a incerteza destes estará sempre presente - e os riscos também. Assim, o praticante prudente precisa considerar o ambiente natural, suas variações e implicações na prática de uma dada modalidade de esporte de aventura.

No que se refere à percepção dos instrutores quanto a situações de risco presentes na prática de esporte de aventura (Tabela 5), nota-se que esses atores, em sua totalidade, percebem que o risco é inerente a referida vertente esportiva, mas que a emoção, a vertigem e aventura experimentadas no momento da prática compensam o risco que se corre. Quanto à conduta a partir da relação que se estabelece entre os itens recomendações de segurança e minimização do risco para si próprio, os instrutores mostraram-se dentro da faixa positiva de comportamento no sentido de prever e/ou minimizar riscos. No entanto, quando se buscou analisar essa mesma consideração para o risco que poderia envolver outras pessoas, os resultados apresentaram significativa variabilidade entre percepção dos mesmos.

Tabela 5

Percepção dos instrutores quanto à situação de risco presente na prática de esporte de aventura.

\begin{tabular}{|c|c|c|c|c|}
\hline \multirow[b]{2}{*}{ CLASSE } & \multicolumn{4}{|c|}{ ITENS INVESTIGADOS - F (\%) } \\
\hline & $\begin{array}{c}\text { O esporte de } \\
\text { aventura é uma } \\
\text { atividade de risco }\end{array}$ & $\begin{array}{l}\text { O praticante coloca-se } \\
\text { em risco quando não } \\
\text { segue recomendações } \\
\text { de segurança }\end{array}$ & $\begin{array}{c}\text { O praticante coloca a } \\
\text { vida de outras pessoas } \\
\text { em risco quando não } \\
\text { segue recomendações } \\
\text { de segurança }\end{array}$ & $\begin{array}{c}\text { A sensação de } \\
\text { liberdade e fortes } \\
\text { emoções compensam } \\
\text { o risco }\end{array}$ \\
\hline Extremamente $(+)$ & $42,20 \%$ & $32,11 \%$ & $16,51 \%$ & $38,53 \%$ \\
\hline Bastante $(+)$ & $57,80 \%$ & $44,03 \%$ & $21,10 \%$ & $61,47 \%$ \\
\hline Um pouco $(+)$ & -- & $23,86 \%$ & $29,36 \%$ & -- \\
\hline Nem um nem outro $(+/-)$ & -- & -- & $11,01 \%$ & -- \\
\hline Um pouco $(-)$ & -- & -- & $22,02 \%$ & -- \\
\hline Bastante (-) & -- & -- & -- & -- \\
\hline Extremamente (-) & -- & -- & -- & -- \\
\hline TOTAL & $100 \%$ & $100 \%$ & $100 \%$ & $100 \%$ \\
\hline
\end{tabular}


A parir da consideração pelos instrutores de que o esporte de aventura é uma prática corporal de risco, é possível afirmar que o risco deliberadamente escolhido para ser vivenciado nessas práticas corporais é mais aceitável que o imposto pelas circunstâncias que possam surgir na vida cotidiana. Ainda que a sensação de liberdade e as fortes emoções compensem o risco com que os praticantes irão se deparar no momento da prática, estes não podem ser considerados suicidas (Bernstein, 1997; Costa, 2000), e sim pessoas que gostam de vivenciar situações de risco que lhes causem prazer. Trata-se do significado do risco-aventura (Spink, 2001; Spink, Medrado, \& Mello, 2002). Eles se lançam em situações que lhes permitem calcular os riscos e lhes dão condições de controlar o imponderável naquele momento. Le Breton (2000) fala da atitude contrafóbica, em que um indivíduo, em vez de evitar ou fugir de situações de risco, lança-se em sua direção. Trata-se de uma maneira refinada de esses indivíduos enfrentarem o medo, dissipando-o e sentindo a provisória sensação agradável de tê-lo dominado.

Em se tratando das recomendações de segurança comuns às modalidades de esporte de aventura no sentido de evitar situações de risco, verificou-se ainda uma postura egocêntrica por parte dos instrutores. Uma vez, que em sua maioria, esses sujeitos foram ou são também praticantes de uma ou mais modalidades de esporte de aventura, eles consideram o risco consigo e não o risco que podem possibilitar às outras pessoas quando as recomendações são ignoradas. Contradizendo tal expectativa verificada nos resultados deste estudo, retoma-se Le Breton (2000), quando afirma que o risco aparece nas sociedades como um dado antropológico e incita o homem à preocupação e responsabilidade para com os outros e consigo mesmo no que se refere à manutenção da integridade física. Parece ainda faltar entre nós, em toda a humanidade, a consciência de senso coletivo. O que está em curso é a forma de se viver na sociedade. Diante desse impasse, Guatarri (2006) percebe que o caminho encontra-se na articulação ético-política entre as três ecologias (o meio ambiente, as relações sociais e a subjetividade humana) pelo homem nessa contemporaneidade. A essa articulação o autor denomina ecosofia.

\section{Considerações finais}

Entre os instrutores de esporte de aventura atuantes no Estado de Minas Gerais, observou-se a prevalência do gênero masculino sobre o feminino na instrução das modalidades. Por ser o risco um elemento inerente à prática de esporte de aventura para a vivência de sensações e superação dos limites humanos e da natureza, os instrutores demonstraram compreender que a integridade física e emocional do praticante está atrelada ao domínio da técnica, ao manuseio dos equipamentos de aporte e segurança e ao conhecimento da região - clima e relevo, no sentido de evitar que os aprendizes se coloquem em situação de risco.

Os riscos na percepção dos instrutores das diferentes modalidades de esporte de aventura praticadas em Minas Gerais, são livremente escolhidos como valor pelos praticantes. Trata-se da forma mais genuína do risco-aventura provido do sentido lúdico, uma vez que a atitude de vivenciar fortes emoções no momento do voo é tomada por esses aventureiros como um risco no qual ousam jogar a si mesmos com total confiança no domínio cada vez maior da técnica e da qualidade dos equipamentos, fruto dos avanços ininterruptos da tecnologia. Manifestam ainda uma atitude audaciosa para poderem desencadear esse risco, autorizada pela ideia confiante de serem capazes de lançar-se no espaço contra os obstáculos da natureza, associada a um excitante e reconfortante prazer de realizar e de tê-lo feito com sucesso a partir do programa de vôo preestabelecido.

Assim, com base nos resultados deste estudo, parece que o maior desafio a ser vencido pelo praticante/ instrutor no decorrer das vivências nessa vertente de esporte está em não perder o sentido e as implicações do risco para sua integridade física. Para além do domínio da técnica, da posse e manipulação de sofisticados equipamentos específicos a uma dada modalidade de voo livre, o praticante precisa conscientizar-se de que o êxito na aventura buscada nessas práticas físicas no meio natural precisa ser buscado na mesma proporção do que o são as fortes emoções, a vertigem e o risco.

Por fim, em decorrência do aumento do número de praticantes das diferentes modalidades que compõem o esporte de aventura e risco na natureza, ressalta-se a importância de desenvolver estudos acadêmicos que busquem, sobretudo, ampliar o entendimento da busca por fortes emoções sob a égide do risco por inúmeros praticantes nessa contemporaneidade.

Para vivenciar de forma plena as sensações proporcionadas pela atividade é importante ter consciência de que o perigo é permanente e que, em alguma hora, a técnica e a coragem não são suficientes para impedir um imprevisto. É preciso atenção, prudência e respeito aos indícios da natureza.

Portanto, é desejável e aconselhável que as entidades, confederações e federações caminhem no sentido da normatização da formação e atuação do instrutor de esporte de aventura, visando não somente a uma padronização, como também ao atendimento pleno daqueles que venham a se interessar por uma ou mais modalidades esportivas do esporte de aventura no Brasil. 


\section{Nota}

1 O entendimento de status não se confunde com o regime jurídico ou contratual que define legalmente a situação do trabalhador. Ainda que possa analisá-lo num conjunto de direitos e obrigações socialmente determinados, o status representa, no fundo, o aspecto normativo da função ou o processo de institucionalização que delineia esse aspecto. Em outras palavras, o status remete à questão da identidade do trabalhador tanto dentro da organização do trabalho quanto na organização social, na medida em que essas funcionam de acordo com uma imposição de normas e regras que definem os papéis e as posições dos atores (Tardif \& Lessard, 2005).

\section{Referências}

Ashcroft, F. M. (2001). Life at the extremes: the science of survival. London: Harper Collins.

Babbie, E. R. (2001). Métodos de Pesquisas de Survey. Belo Horizonte: Editora UFMG.

Beck, U. (1993). Risk society: Towards a new modernity. London: Sage.

Bentley, T. A., Macky, K., \& Edwards, J. (2006). Injuries to New Zealanders participating in adventure tourism and adventure sports: an analysis of accident compensation corporation claims. New Zealand Medical Journal, 119 (1247), 56-68.

Bentley, T. A. \& Page, S. J. (2008). A decade of injury monitoring in the New Zealand adventure tourism sector: a summary risk analysis. Tourism Management, 29, 857-869.

Bentley, T. A., Page, S. J., \& Laird, I. S. (2001). Accidents in the New Zealand adventure tourism industry. Safety Science, 38, 31- 48 .

Bernstein, P. L. (1997). Desafio dos deuses: a fascinante história do risco ( $2^{\mathrm{a}}$ ed.). Rio de Janeiro: Campus.

Betrán, A. O. \& Betrán, J. O. (1995). Propuesta de un classificación taxonômica de las actividades físicas de aventura em la natureza. Marco conceptual y análisis de los critérios elegidos. Dossier Las Actividades Físicas de Aventura en la Naturaza: análisis sociocultural. Apunts: Educación Física y Deportes, 41, 108-123.

Callois, R. (1988). Philosophic Inquiry in Sport. Champaign/ Illinois: Human Kinetics Publisher.

Cliff, S. \& Page, S. J. (1996). Health and the international tourism. Routledge: London.

Costa, L. C. A. (2005). Prática pedagógica de professores de educação física no ensino fundamental: contribuição da formação inicial e continuada. Tese de Doutorado, Programa de Pós-Graduação em Educação Física, Universidade Federal de Santa Catarina, Florianópolis, Brasil.

Costa, V. L. M. (2000). Esportes de aventura e risco calculado na montanha: um mergulho no imaginário. São Paulo: Manole.

Drake, J. E. \& Miller, F. J. (1969). Marketing research: Intelligence and management. Stranton, PA: International Textbooks.

Duffield, C. (1993). The Delphi Technique: a comparison of results obtained using two expert panels. Luft.J.Nursing Study, 30, 227-237.

Elias, N. (1993). Processo civilizador: história dos costumes (Vol. 1). São Paulo: Jorge Zahar Editor.

Elias, N. (1997). A busca da excitação no esporte. Lisboa: Difel.

Elmes, M. \& Barry, D. (1999). Deliverance, denial and the death zone: a study of narcissism and regression in the 1996 Everest climbing disaster. Journal of Applied Behavioural Science, 35(2), 163-187.

Ewert, A. (1985). Why people climb: The relationship of participant motives and experience level to mountaineering. Journal of Leisure Research, 17(3), 241-250.

Foucault, M. (2007). A microfisica do poder (23 ${ }^{\mathrm{a}}$ ed.). Rio de Janeiro: Graal.

Giddens, A. (1991). As conseqüências da modernidade. São Paulo: UNESP.

Giddens, A. (2002). Modernidade e identidade. Rio de Janeiro: Jorge Zahar Editor.

Gil, A. C. (2008). Métodos e técnicas de pesquisa social (6 $6^{\mathrm{a}}$ ed.). São Paulo: Atlas.

Guattari, F. (2006). As três ecologias (17 ed.). Campinas, SP: Papiros.

Horn, T. S. (2002). Advances in sport psychology. Champaign: Human Kinetics.

Huizinga, J. (1988). Cultural analyses: Play, game and sport. In W. J. Morgan, \& K. V.Meier (Eds.), Philosophic Inquiry in Sport (pp. 32-46). Champaign/Illinois: Human Kinetics Publisher.

La Mendola, S. (2005). O sentido do risco. Revista de sociologia da USP, 17(2), 59-91.

Le Breton, D. (2000). Passions du risque. Paris: Métailié.

Le Breton, D. (2004). Conduites à risque. Paris: Presses Universitaires de France.

Le Breton, D. (2006). A sociologia do corpo. Petrópolis, RJ: Vozes.

Malhotra, N. K. (2001). Pesquisa de marketing: uma orientação aplicada. Porto Alegre: Bookman.

Mandell, R. (1986). História cultural del deporte. Barcelona: Ediciones Bellaterra.

Marinho, A. \& Bruhns, H. T. (2003). Turismo, lazer e natureza. São Paulo: Manole.

Morgan, D. \& Fluker, M. (2006). Risk management for Australian commercial adventure tourism operation. Journal of Hospitality and Tourism Management 29(5), 153-168.

Page, S. J., Bentley, T. A., \& Walker, L. (2003). Scoping the nature and extent of adventure tourism operations in Scotland: How safe are they? Tourism Management, 26(3), 381-397.

Parlebás, P. (2001). Juegos, deporte y sociedad: léxico de praxiologia motriz. Barcelona: Paidotribo.

Ryan, C. (2003). Risk acceptance in adventure tourism - Paradox and context. Managing tourist health and safety in the new millennium, 26(3), 473-474.

Sánchez Martín, R. (1996). Los usos sociales del riesgo: el deporte de aventura como configurador de uma ética de la contingencia. In R. S. Martín (Ed.), La actividad física y el deporte en un contexto democrático (1976-1996) (pp. 251-274). Pamplona: Edita; Aeisad.

Souza, F. R. (2004). O imaginário no rafting: uma busca pelos sentidos da aventura, do risco e da vertigem. São Paulo: Zouk.

Spink, M. J. (2000). Contornos do risco na modernidade reflexiva: contribuições da psicologia social. Psicologia \& Sociedade, 12(1/2), 156-173.

Spink, M. J. (2001). Trópicos do discurso sobre risco: riscoaventura como metáfora na modernidade tardia. Caderno de Saúde Pública, 17(1), 277-311.

Spink, M. J., Medrado, B., \& Mello, R. P. (2002). Perigo, probabilidade e oportunidade: a linguagem dos riscos na mídia. Psicologia, Reflexão e Crítica, 15(1), 151-164.

Spink, M. J. \& Menegon, V. M. (2004). Práticas discursivas como estratégias de governamentalidade: a linguagem dos 
riscos em documentos de domínio público. In L. Inigues (Org.), Manual de análise do discurso em ciências sociais (pp. 258-311). Petrópolis, RJ: Vozes.

Tardif, M. \& Lessard, C. (2005). O trabalho docente: elementos para uma teoria da docência como profissão de interações humanas. Petrópolis, RJ: Vozes.

Thomas, J. R. \& Nelson, J. K. (2002). Métodos de pesquisa em atividade fisica ( $3^{\mathrm{a}}$ ed.). Porto Alegre: Artmed.

Wilks, J. \& Atherton, T. (1994). Health and safety in marine tourism: A social, medical and legal appraisal. Journal of Tourism Studies, 5(2), 2-16.

Recebido em: 10/11/2009

Revisão em: 17/03/2010

Aceite em: 27/06/2010

Jairo Antonio da Paixão é graduado em Educação Física e em Pedagogia pela Universidade Federal de Viçosa. Doutorado em Ciência do Desporto pela Universidade de Trás-os -Montes e Alto Douro em Portugal. Professor adjunto da Universidade Federal de Ouro Preto. Campus Universitário, Morro do Cruzeiro s/n. Ouro Preto/MG, Brasil. Email: jairopaixao2004@yahoo.com.br

Ronaldo Eugênio Calçada Dias Gabriel é Licenciado em Educação Física pelo ISEF/UTL. Doutor em Ciências do Desporto - Biomecânica. Professor Associado na Área de
Biomecânica do Exercício e do Desporto na Universidade de Trás-os -Montes e Alto Douro, Vila Real, Portugal.

Guilherme Tucher é licenciado em Educação Física pela Fundação Universitária de Itaperuna, RJ. Mestre em Ciência da Motricidade Humana. Doutorando em

Ciência do Desporto pela Universidade de Trás-os

-Montes e Alto Douro em Portugal. Professor do Curso de Licenciatura e Bacharelado em Educação Física da Faculdade de Minas, Muriaé/MG.

Marizabel Kowalski é Licenciada em Educação Física pela Universidade Estadual de Ponta Grossa/PR. Mestre em Educação Motora pela Universidade Metodista de Piracicaba/ SP. Doutora em Educação Física: Sociedade, Cultura e Esporte pela Universidade Gama Filho/RJ. Professora do Programa de Pós-Graduação Universidade Federal de Viçosa.

Vera Lucia de Menezes Costa é graduada em Educação Física pela Universidade Federal do Rio de Janeiro. Mestrado em Educação pela Universidade Federal do Rio de Janeiro e doutorado em Educação Física pela Universidade Gama Filho.

\section{Como citar:}

Paixão, J. A., Gabriel, R. E. C. D., Tucher, G., Kowalski, M. \& Costa, V. L. M. (2011). Risco e aventura no esporte na percepção do instrutor. Psicologia \& Sociedade, 23(2), 415-425. 